\title{
BIOÉTICA Y TECNOCIENCIA
}

BIOETHICS AND TECHNOSCIENCE

\section{BIOÉTICA E TECNOCIÊNCIA}

Victor B. Penchaszadeh*

\section{Introducción}

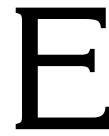

desarrollo de la tecnociencia en los últimos decenios ha sido vertiginoso y los problemas y dilemas bioéticos que plantea a la humanidad son incontables. Sin embargo, el pensamiento bioético está recién comenzando a analizar la trascendencia de los adelantos científico-técnicos; particularmente en relación a problemáticas de frontera, tales como: las tecnologías de fertilización asistida, las investigaciones con células madre, el mantenimiento de la vida con técnicas artificiales, entre otras. Temas cardinales como la humanización de la medicina, el derecho a la salud, la influencia nociva de la comercialización y la medicalización excesiva no forman parte hegemónica del discurso bioético. Es preocupante que la formación de los profesionales de

* Médico, Universidad de Buenos Aires, Argentina, Master of Science en Salud Pública, School of Higiene and Public Health, Johns Hopkins University, Baltimore, médico cirujano (por reválida), Universidad Central de Venezuela, Certificación en Bioética y Humanidades Médicas, Columbia University, Nueva York. Presidente, Red Latinoamericana y del Caribe de Bioética UNESCO.

Correo electrónico: victorpenchas@gmail.com

Artículo recibido el 30 de junio de 2016 y aprobado para su publicación el 15 de julio de 2016. 
salud mayoritariamente ignora la importancia de la bioética secular fundamentada en los derechos humanos, que debiera ser el eje de la capacitación para prestar atención de salud. Éste artículo se focalizará en la genómica, una rama de la tecnociencia de gran predicamento actual.

\section{Bioética y genómica}

La genómica es una de las tecnociencias de mayor desarrollo reciente y que mayores dilemas bioéticos está generando. De acuerdo a la Organización Mundial de la Salud, el objetivo de la genética en el campo de la salud es: "ayudar a la gente con una desventaja de origen genético a vivir y reproducirse lo más normalmente posible" (WHO, 2002), lo cual obviamente incluye: la prevención de enfermedades, la promoción y reparación de la salud, y el respeto de los derechos humanos y la dignidad de las personas. Desde la bioética, esta formulación implica dejar de lado objetivos autoritarios y represivos anteriormente usados. En efecto, en el pasado la genética, aunque aún pobremente comprendida, fue utilizada para interferir con el derecho a la reproducción y determinar quienes podían reproducirse y quienes no, en aras de mal concebidas concepciones eugenésicas. Así, se privilegiaron objetivos clasistas y racistas por sobre los derechos, la salud y el bienestar de las personas. La genética también fue utilizada para justificar la esclavitud, el racismo y para discriminar y estigmatizar a personas con enfermedades genéticas (Duster 1050-1051).

Es por ello que las estrategias de la genómica en el cumplimiento del objetivo enunciado por la OMS incluyen: la pesquisa neonatal de enfermedades congénitas, las pruebas genéticas diagnósticas, las pruebas genéticas predictivas, la predicción de respuestas a determinados fármacos -farmacogenética-, la pesquisa prenatal de anomalías cromosómicas durante la gestación, el diagnóstico genético prenatal, el asesoramiento genético y el tratamiento de enfermedades genéticas.

Estas aplicaciones, y las que se desarrollarán en el futuro, han requerido y seguirán requiriendo investigaciones en seres humanos para asegurar su validez y su inocuidad. Los dilemas bioéticos que enfrenta la genómica en la 
actualidad se comprenden mejor cuando se analizan los principales objetivos y métodos que emplea esta tecnociencia en sus aplicaciones sanitarias.

\section{Objetivos y métodos de la genómica en salud}

1. Conocimiento de la estructura y función del genoma humano.

2. Identificación de mutaciones en genes que determinan enfermedades monogénicas.

3. Identificación de genes que predisponen a contraer enfermedades multifactoriales con interacción genético-ambiental.

4. Determinación de la validez y utilidad clínica de las pruebas genéticas diagnósticas y predictivas en enfermedades monogénicas y multifactoriales.

5. Determinación del valor predictivo de ciertas variantes genéticas 'normales' (polimorfismos) en enfermedades y en la respuesta a fármacos.

6. Desarrollo de nuevas terapéuticas:

- Terapia génica

- Edición genética

- Investigación en células madre para clonación terapéutica

7. Desarrollo de métodos de prevención de enfermedades complejas comunes basados en genómica.

8. Evaluación de resultados de intervenciones preventivas o terapéuticas.

10. Diversidad genética de la especie humana y significado biológico del concepto de «raza».

11.Identificación humana. Genética forense. Uso de la identificación genética humana para la defensa de derechos humanos.

\section{Métodos de las investigaciones genéticas y sus sesgos}

Gran parte de los descubrimientos en genética humana se han llevado a cabo mediante el análisis del material genético en pacientes con enfermedades genéticas. Los adelantos tecnológicos ocurridos en los últimos 50 años han permitido pasar del análisis de los cromosomas al 
análisis molecular de un gen y luego de varios genes, posteriormente de centenares o miles de genes a la vez, y finalmente al análisis del genoma completo de una persona. En la búsqueda de genes responsables de enfermedades, estas investigaciones comparan el genoma de grupos de pacientes con una enfermedad con el genoma de personas sanas, infiriendo que las diferencias encontradas en el material genético entre ambos grupos son la base de la enfermedad. Desde el punto de vista metodológico, estas investigaciones son sumamente complejas, donde intervienen numerosos factores. Éstos incluyen, entre otros: la definición de la enfermedad investigada, la selección de las poblaciones a estudiar, la selección de las variables a analizar, la consideración de los factores ambientales del contexto, y como éstos interactúan con el genoma para influenciar el fenotipo -es decir, las manifestaciones clínicas de la enfermedad-. Es fácil reconocer que, frente a cada uno de los factores mencionados, el investigador tiene que tomar decisiones metodológicas y conceptuales que implican valoraciones subjetivas y están sometidas a numerosos sesgos. Esto implica que muchas veces los resultados deben someterse a filtros epistemológicos para determinar su validez.

Uno de los métodos más utilizados para estimar la participación de factores genéticos en características humanas, normales y patológicas es el estudio de mellizos. Éstos tienen variaciones metodológicas. Los más comunes comparan la presencia o ausencia de la característica en estudio -sea obesidad, depresión, diabetes, etc.- en poblaciones de mellizos, comparando los resultados de acuerdo a si son monocigóticos o dicigóticos. La comparación de la concordancia -proporción en que la enfermedad está presente en ambos miembros del par de mellizos- y la discordancia -proporción en que la enfermedad está presente en sólo un miembro del par- entre mellizos monocigóticos -que tienen genoma idéntico- y mellizos dicigóticos -cuyo genoma es solo 50\% idéntico-, es la base para estimar los componentes genéticos y ambientales de la característica en estudio. El problema con muchos de estos estudios es que los presupuestos en que se basan adolecen de serios sesgos, dado que la concordancia entre mellizos para un rasgo determinado, puede ser debida no solo a la semejanza genética sino también a la influencia de factores ambientales a los cuales estén expuestos ambos. Las variaciones 
metodológicas diseñadas para mitigar estos sesgos, como el estudio de mellizos criados aparte, no han podido capturar la complejidad de los contextos en que transcurre la vida humana.

Otro método actual para investigar el papel de factores genéticos en el desarrollo de enfermedades comunes es la llamada secuenciación de nueva generación, que puede aplicarse al exoma completo -conjunto del ADN codificante en el genoma- o al genoma completo -total del ADN codificante y no codificante del genoma-. La comparación de exomas o genomas completos de personas sintomáticas con alguna de esas enfermedades, con los de personas afectadas, puede detectar la causa genética de la enfermedad en los afectados. Se supone que las variaciones genéticas presentes en los enfermos, y no en los sanos, serían los factores genéticos responsables de la enfermedad. Este método, sin embargo, está plagado de presupuestos e inferencias estadísticas arbitrarias que dificultan conclusiones certeras. En todo caso, la mayoría de las variaciones genéticas descubiertas hasta ahora para distintos tipos de cáncer, enfermedad de Alzheimer, enfermedad coronaria, entre otras; no parecen aumentar significativamente el riesgo de la enfermedad en cuestión. Más importante aún, la presencia de esas variaciones genéticas, supuestamente predisponentes, no implica necesariamente la existencia de intervenciones preventivas o terapéuticas en las personas en riesgo.

El papel relativo de los componentes genéticos y ambientales en la determinación de muchas características humanas todavía es muy discutido. Esto es particularmente cierto en enfermedades comunes -como el cáncer, la enfermedad coronaria, la diabetes y muchas otras- y en rasgos de la conducta, normal o patológica -inteligencia, personalidad, orientación sexual, psicosis-. Este atolladero tiene su fundamento en una concepción reduccionista de los fenómenos de salud-enfermedad, con una visión excesivamente biologicista del ser humano, que desdeña el papel fundamental del medio ambiente en el que se desarrolla la persona, especialmente las condiciones sociales de vida y trabajo y el acceso a los servicios de salud (Lewontin). Observaremos más adelante que esta concepción denominada reduccionismo genético es responsable de muchas falacias bioéticas. 
Aparte de las generalidades de la ley sobre los aspectos éticos de toda investigación biomédica, las investigaciones genéticas confrontan dilemas éticos especiales, en gran medida por el significado particular del material genético. En efecto, el ADN ha sido investido por la sociedad con un aura especial, por su carácter permanente en las personas, por ser parte de su identidad, por ser identificador de origen étnico, por ser trasmitido hereditariamente, por informar sobre la filiación de las personas y por indicar posibles predisposiciones genéticas a ciertas enfermedades. Todas estas características hacen que las investigaciones en que se obtienen muestras de ADN de las personas requieran escrutinio ético especialmente riguroso. En las siguientes secciones analizaremos la relación entre la bioética y la tecnociencia genómica (Penchaszadeh, "Ética de la Investigación en Biomedicina").

\section{El énfasis excesivo en los determinantes genéticos de enfermedad no tiene justificación científica ni bioética}

En los últimos tiempos, y en gran medida por el desarrollo de la tecnociencia y la influencia de intereses económicos, los profesionales de la salud, los investigadores y la sociedad entera, estamos sujetos a la noción de que las principales causas de las desviaciones de la salud se encuentran en la biología de los individuos. Un fenómeno cada vez más evidente es que en el espectro de lo biológico los genes han adquirido fama inmerecida de «hacedores» de vida, por sobre muchos otros procesos vitales postgenómicos fundamentales, como aquéllos que determinan las estructuras espaciales y las funciones de las proteínas, o que regulan nuestro metabolismo y la interacción con el medio ambiente. En efecto, algunos investigadores dirigen su atención en forma sesgada a los genes, como primer paso para explicar cualquier fenómeno humano, desde variaciones en las conductas -como la solidaridad, la agresividad o la inventiva-, hasta posibles causas de enfermedades, en lugar de los determinantes sociales de las mismas. Con el mismo paradigma, se tiende a recurrir primero a los genes y no al medio ambiente, toda vez que se 
trata de diseñar estrategias de prevención y tratamiento de enfermedades (Evans, et al. 861-862.).

Pocas concepciones han hecho más daño a la ciencia y a la sociedad que el reduccionismo genético. Se trata de una ideología reaccionaria y pseudocientífica que sostiene que la explicación de los fenómenos humanos puede reducirse a los efectos de los genes, tanto a nivel evolutivo como en la vida actual, relegando el efecto del contexto ambiental y social a un papel secundario. Al poner a los genes en un pedestal inmerecido el reduccionismo olvida que lo único que hacen los genes es transmitir una información a la célula para que esta fabrique proteínas que a su vez serán la base de los procesos vitales. Al reducir el ser humano a los efectos de los 25 mil genes que componen nuestro genoma, el reduccionismo se desentiende de la noción sostiene que la esencia dialécticamente indivisible del hombre es la de ser un ente bio-psico-social y que los principales determinantes de la conducta y las enfermedades se encuentran en las variaciones del medio ambiente social, económico, político, psicológico y biológico, más que en las variaciones genéticas. (Penchaszadeh, "Genética y Derechos Humanos".)

Efectivamente, si nos preguntamos de qué se enferman y se mueren las personas, veríamos que el mantenimiento de la salud depende fundamentalmente de factores medioambientales, sociales y económicos, más que de la constitución genética de las personas. De acuerdo a la Organización Mundial de la Salud las 10 principales causas de muerte en el mundo en todas las edades son: infarto de miocardio (12.2\%), accidentes vasculares cerebrales $(9.7 \%)$, neumonía $(7.1 \%)$, enfermedad pulmonar obstructiva crónica (5.1\%), VIH/SIDA (3.5\%), tuberculosis (2.5\%), cáncer de pulmón (2.3\%), accidentes de tránsito (2.2\%), y prematuridad y bajo peso al nacer $(2.0 \%)$. Si analizamos solo las muertes en los primeros 5 años de vida, donde los defectos congénitos y las enfermedades genéticas tienen mayor peso, vemos que las 6 primeras causas de muerte -entre los 10 millones de niños en ese grupo de edad que fallecen por año- constituyen el $75 \%$ de las muertes y son, en orden decreciente: infecciones respiratorias (17\%), diarreas (17\%), bajo peso al nacer $(11 \%)$, 
infecciones del recién nacido (9\%), asfixia del recién nacido (8\%) y malaria o paludismo (7\%). (Penchaszadeh, "Genética y Salud")

¿Cómo figuran las enfermedades genéticas en este cuadro? Si nos atenemos a la definición más restrictiva de enfermedad "genética» podríamos decir que por lo menos un $5 \%$ de la mortalidad en menores de 5 años es debido a trastornos genéticos y defectos congénitos de causa desconocida. Esto no es mucho ni poco. La importancia de los problemas de salud no se mide solamente por su frecuencia ni por su impacto en la mortalidad. Otros factores importantes están relacionados con: la gravedad de las manifestaciones clínicas, la invalidez o discapacidad que ocasionan durante la vida, la dificultad de su prevención, y la complejidad y costo de su tratamiento. Las enfermedades hereditarias afectan negativamente la autoestima de los afectados y sus familiares, generando sentimientos de culpa y ansiedad, a los que se agregan el estrés de la estigmatización y discriminación de que suelen ser objeto por la sociedad. Obviamente, no es ético ni acorde al derecho humano a la salud, argumentar que como las enfermedades genéticas son poco frecuentes, no merecen la atención de los profesionales y los organismos de salud. (Penchaszadeh, "Genética y Salud"; "Genética y Derechos Humanos" 177-204).

La importancia numérica de los trastornos genéticos aumentaría si incluyéramos las enfermedades comunes con contribución de factores genéticos, pues en ese caso contarían también: el cáncer, las enfermedades cardiovasculares, la diabetes, y muchas otras. Sin embargo, los determinantes principales de éstas son sociales y medioambientales: exposición a tóxicos y mutágenos -agentes causantes de mutaciones-, condiciones de vida y trabajo, educación, vivienda, alimentación, ejercicio, etc.

Uno de los varios problemas bioéticos del reduccionismo es que al reducir el ser humano a sus genes distorsiona las prioridades de investigación al preferenciar lo genético, desconecta a la persona y las enfermedades del contexto social y se desinteresa del estudio de los determinantes ambientales de enfermedad y la interacción genética-ambiente. 


\section{La discriminación y la estigmatización genéticas son profundamente antiéticas}

Uno de los riesgos éticos de las investigaciones genéticas es que la información obtenida se utilice en perjuicio de los participantes, por ejemplo por parte de seguros privados de salud para negar la cobertura de servicios o cobrar cifras astronómicas por las pólizas a personas con características genéticas «inconvenientes». Lamentablemente, el hecho que la salud está dejando de ser un derecho, para convertirse en un objeto de mercado, genera las condiciones para que los seguros privados con fines de lucro tengan el incentivo económico para discriminar a las personas con mayor riesgo de enfermar, incluyendo a aquellos con susceptibilidades genéticas para desarrollar enfermedades (Geller ctd en Alper 267-282). La discriminación genética en el mercado laboral es otra posible consecuencia de las investigaciones genéticas, reñida con la ética. Aunque la tecnología todavía no permite predicciones válidas, son varias las industrias norteamericanas que han recurrido a pruebas genéticas para deshacerse de trabajadores que consideraban «riesgosos» para sus ganancias (Holtzman). Las investigaciones genéticas deben asegurar la protección de la privacidad de los datos genéticos para así minimizar su utilización en la discriminación de las personas (UNESCO, "Declaración internacional sobre datos genéticos humanos").

Detrás de cada evento de discriminación genética subyace una concepción reduccionista y determinista del papel de la constitución genética en el proceso de salud-enfermedad. No sólo es una aberración bioética que conspira contra los principios de justicia, equidad y solidaridad, sino que además se basa en la falacia pseudocientífica de que los genes son los principales determinantes de la salud de los individuos y las poblaciones.

\section{Bioética y bases de datos genéticos}

El volumen y la complejidad de la información que se obtiene actualmente en las investigaciones genéticas son inmensos y proporcionales a la 
dificultad de la estructura y función del genoma y de las interacciones entre el genoma y el medio ambiente. La identificación de millones de «marcadores» a lo largo del genoma ha llevado a la creación de bases computarizadas de datos genéticos, donde se almacena información de centenares de miles de individuos con diversos fines. Los principales objetivos de estas bases de datos son: (a) la identificación de personas -uso forense-; (b) la investigación de genes asociados a enfermedades comunes; y (c) la identificación de genes de respuesta a fármacos y tóxicos. Las bases de datos pueden contener sólo información sobre personas, o contener además las muestras de $A D N$ de las mismas.

Diversas características de la información genética hacen que se deba tratar con sumo cuidado para no infringir principios bioéticos y derechos humanos fundamentales. Estas características son:

- Su carácter permanente

- Su relación con la identidad de la persona

- Su posible capacidad predictiva de fenotipos aún no aparentes: Enfermedades, capacidad cognitiva, etc.

- Su información trasciende al individuo y puede afectar a la familia, la comunidad y el grupo étnico, entre otros.

La relación entre la bioética y la tecnociencia de las bases de datos genéticos están relacionadas con: (a) los objetivos de las mismas; y (b) los procedimientos para su desarrollo y utilización. En cuanto a los objetivos, para que una base de datos genéticos sea ética debe propender al bien, es decir, contribuir a la vigencia de los derechos humanos, la salud y el bienestar. Por ejemplo, en Argentina se creó en 1987 una base de datos genéticos con un objetivo ético de defensa de derechos humanos para ayudar en la identificación y recuperación de niños que fueron apropiados por personas allegadas a las fuerzas de represión durante la última dictadura militar. El Banco Nacional de Datos Genéticos almacena información y muestras de ADN de los familiares -mayoritariamente abuelos- que buscan a sus nietos o hijos desaparecidos. La base de datos es pública y está financiada por el Estado con la participación de Abuelas de Plaza de Mayo; ha permitido la identificación y restitución de por lo menos 119 personas que fueron secuestradas y apropiadas por 
la dictadura pasada cuando eran niños (Abuelas 1-205; Penchaszadeh, "Genética y Derechos Humanos" 87-112).

Por otra parte, se están creando bases de datos genéticos en varios países con fines en investigación genómica. Los problemas éticos de estos proyectos están relacionados fundamentalmente con la obtención, contenido, propiedad y utilización de la información genética de los individuos y poblaciones incluídas en la base de datos. Existen cuestionamientos acerca de cómo y quién consiente a ser incluído en una base de datos y qué tipo de consentimiento otorga. En Islandia, por ejemplo, después de un proceso político y económico sumamente complejo, y con la oposición de importantes sectores médicos, una compañía privada de capitales norteamericanos, DeCode, obtuvo una licencia exclusiva para el desarrollo de la base de datos y su explotación comercial. La sección de la base de datos que contiene los datos personales de salud de las personas no requería consentimiento informado, aunque existía la posibilidad de negarse a participar (Annas). En 2007 la Corte Suprema de Islandia dictaminó que esa ley era inconstitucional; como consecuencia, las acciones en bolsa de DeCode han bajado sustancialmente. Un segundo aspecto ético a considerar en las bases de datos genéticos, es el riesgo de discriminación y estigmatización de individuos y comunidades por sus características genéticas. Para prevenir e impedir la discriminación es necesario respetar la privacidad de la información genética y promulgar medidas legislativas apropiadas (UNESCO, "Declaración internacional sobre datos genéticos humanos"). Sin embargo, aunque estas declaraciones proclaman que las bases de datos genéticos deben ser consideradas bienes públicos, no abordan explícitamente el problema de la apropiación privada y la comercialización de la información y sus aplicaciones.

Con el auge de la tecnociencia varios gobiernos han implementado, o están considerando desarrollar, bases de datos que contengan el ADN de infractores a las leyes. Se piensa que de esa manera, cuando un criminal reincide será más fácil identificarlo por muestras de tejido que puede haber dejado en la escena del crimen y traerlo a la justicia. En Inglaterra se han esclarecido así varias decenas de crímenes no resueltos previamente. Sin embargo, no hay ninguna evidencia que la mera existencia de bases 
de datos con ADN de delincuentes actúe como disuasor de actividades delictivas, lo que quiere decir que el poder "preventivo» de las bases de datos es por ahora un artículo de fe más que una certeza. Los gobiernos conservadores en todo el mundo encuentran más expeditivo para combatir el delito los métodos represivos -uno de cuyos instrumentos son las bases de dato-), en lugar de implementar medidas que vayan a las raíces del delito, es decir a atacar la pobreza, la injusticia social, la concentración de la riqueza en cada vez menos manos y la falta de oportunidades de educación y trabajo para los jóvenes. Este enfoque no sólo es poco efectivo sino que corre el riesgo bioético de que las bases de datos avasallen derechos fundamentales -privacidad, derecho a no ser estigmatizado injustificadamente- y que reemplacen los programas sociales y económicos para la prevención del delito (OECD).

Es posible que las bases de datos genéticos aplicadas a la investigación biomédica redunden en conocimientos aplicables a la salud. En los casos que ello sea efectivamente así, es imprescindible que existan previsiones para compartir eventuales beneficios de los resultados de estas investigaciones con los sujetos y las comunidades que contribuyen sus muestras para las mismas.

Dado que los investigadores en algunos países de América Latina están considerando proyectos de bases de datos genéticos es importante que se desarrollen instrumentos regionales que evalúen los objetivos, estructura y funcionamiento de las mismas y sus implicaciones éticas, legales y sociales. Finalmente, cabe preguntarse si la creación de bases de datos genéticos obedece a un uso racional y ético de recursos económicos escasos, y si su mera existencia no refuerza concepciones reduccionistas de la importancia de las variaciones genéticas en las características humanas.

\section{Bioética y manejo de muestras genéticas}

Virtualmente todas las investigaciones genéticas humanas recurren a análisis en muestras biológicas de los participantes. Las investigaciones 
que se realizan con muestras biológicas humanas están sujetas a una serie de recaudos éticos que tienen como principal objetivo asegurar la privacidad del donante de la muestra evitando su identificación por individuos o instituciones, sin la autorización del donante. Esta autorización puede darse en el contexto del consentimiento informado otorgado por el participante. El punto clave previo es determinar si la fuente de la muestra será identificable y, si el proveedor de la muestra es identificado, cuáles pueden ser los daños al mismo.

En la determinación de los riesgos de daño al proveedor de la muestra, importa saber cuán fácilmente identificable es la fuente y la posibilidad de que la fuente sea localizada. Si la fuente es localizada, se debe preguntar por la probabilidad de que otras personas además del investigador obtengan información sobre la fuente cicuán probable es que si la fuente es localizada, le ocurran daños, incluyendo consecuencias adversas por comunicarse resultados inciertos o ambiguos? Estas consideraciones guiarán al investigador y al comité de evaluación ética de la investigación en la decisión de requerir consentimiento informado y los contenidos del mismo.

Por otra parte, es frecuente que eventualmente se plantee el uso de muestras en estudios futuros. En estos casos, no es ético utilizar muestras obtenidas para una investigación particular, para otras investigaciones futuras sobre temas diferentes al que consta en el consentimiento informado original. En estos casos, la nueva investigación requerirá otro consentimiento informado, este deberá ser obtenido por el investigador nuevamente para ésa investigación.

Bioética e información de resultados de pruebas genéticas en una investigación

Los resultados de las investigaciones genéticas todavía tienen poca utilidad práctica en prevención y tratamiento. No sólo los resultados pueden ser ambiguos, inciertos, o de difícil interpretación, sino que los hallazgos iniciales pueden no tener significación para la salud hasta que 
no se confirmen y muchas variantes génicas en estudio son de baja penetrancia, por lo que su incidencia en el fenotipo en estudio es baja. Si a lo anterior se agrega que los laboratorios de investigación no están sujetos a los controles estrictos de calidad a los cuales están sujetos los laboratorios clínicos y que la comunicación de resultados no concluyentes o no-interpretables puede ser perjudicial, se entiende porque, en general, los resultados de las investigaciones no se revelan a los sujetos de estudio. Las excepciones a esta política son cuando:

- los hallazgos son científicamente válidos y han sido confirmados por otros investigadores en forma independiente.

- los hallazgos tienen gran significación para la salud del sujeto.

- el conocimiento del resultado permite mejorar o tratar el problema de salud mediante una intervención de efectividad comprobada.

En cualquier caso, la revelación de resultados de investigación genética debe ir acompañada de consejo médico o referencia, incluyendo asesoramiento genético. Una opción intermedia favorecida por algunos autores es comunicar resultados a cada participante sólo en agregado, incluyendo la recomendación de hacerse análisis en un laboratorio clínico si los resultados individuales lo justifican.

\section{El patentamiento de genes es contrario a los principios de la bioética}

En los años 80's se hicieron aparentes las posibilidades comerciales de la manipulación genética y las ventajas que otorgaría a la industria la aplicación del sistema de patentes a los descubrimientos genómicos. Esto fue seguido en los últimos 20 años del patentamiento de miles de genes, segmentos de genes y proteínas producidas por genes. Esto ha ocurrido en un contexto global regido por el afán de lucro, la primacía del mercado por encima de cualquier valor humano y la acción de las oficinas de patentes de Estados Unidos y Europa de favorecer a la industria por encima del bien público. Las consecuencias de estas acciones monopólicas han sido el encarecimiento de los productos -fármacos y pruebas diagnósticas-, 
la inequidad en el acceso a los productos por parte de grandes sectores de la población mundial y las trabas a la investigación científica. Estos desarrollos claramente contrarios al bien público han podido ocurrir gracias a la violación sin desparpajos de los principios básicos de la propiedad intelectual y de las reglas de patentamiento.

Analicemos los principios y los hechos. De acuerdo a los principios de la propiedad intelectual, una patente es como un «premio» a la inventiva humana, gracias a la cual el inventor de un producto puede usufructuar su invento sin competencia durante un período determinado, típicamente 20 años. Para ser elegible para patentamiento, el invento debe:

- Ser novedoso.

- Ser inventivo, ingenioso, no obvio.

- Tener una función conocida, ser útil o tener aplicación industrial.

- Ser revelado en todos sus detalles en la solicitud de patente.

Ahora bien, cंel ADN ha sido acaso «inventada» por alguien, que puede entonces reclamar una patente? En función de la naturaleza inalienable del ADN, declarado por la UNESCO patrimonio común de la humanidad, es dudoso que tenga los atributos requeridos para ser patentado. En efecto, los genes son entidades que ocurren en la naturaleza y se descubren, no se inventan. Sin embargo, la posición de las oficinas de patentes ha sido que no se patentan los genes tal como ocurren naturalmente, sino moléculas creadas artificialmente por clonación y aislados del cuerpo humano. Esta afirmación claramente exagera el papel del científico que aísla un segmento de ADN y lo purifica. En rigor de verdad, la tan mentada purificación no es más que limpiar el ADN natural de secuencias que no están relacionadas con la información genética propiamente dicha. Es decir, que el producto del ADN natural y el ADN purificado es exactamente el mismo. Lamentablemente, lo ocurrido hasta ahora con las patentes de ADN demuestra que cuando los intereses son poderosos los argumentos se tuercen como sea necesario para hacer prevalecer esos intereses. Durante más de 20 años, las oficinas de patentes han hecho todo lo posible para favorecer a los intereses de la industria, bajando escandalosamente los requisitos para otorgar patentes de ADN. Las 
patentes otorgadas tienen una cobertura demasiado amplia y los criterios de inventividad y utilidad han tenido umbrales muy bajos. El inventor adquiere derechos para todos los usos del ADN y las proteínas que este codifica, circunstancia insólita por el poder que adquiere. En efecto: se impide o dificulta el desarrollo de nuevos medicamentos y tratamientos; se limita el acceso a servicios de salud al aumentar el costo de pruebas diagnósticas y tratamientos; se explota el conocimiento, contradiciendo la tradicional máxima que el conocimiento no es patentable; y se inhibe el libre intercambio entre investigadores. Por otra parte, se ha creado un clima de batallas legales extensas y costosas, con industrias competidoras peleando por patentes sobre un mismo gen o parte de un gen, hasta el punto que hay genes que tienen más de una decena de patentes sobre distintos segmentos del mismo.

\section{La investigación en genética de la conducta presenta serios problemas bioéticos}

El reduccionismo ha calado muy hondo como explicación de las causas de la diversidad humana en gustos, personalidad, orientación sexual, criminalidad, adicciones, y muchas otras características. Pare el reduccionismo, la variación en todas ésas está indudablemente en los genes. Las influencias del medio ambiente, expresado en variaciones en las condiciones de vida y trabajo, el nivel social y económico, cultura, educación, nutrición, crianza, enfermedades, opresión, entre otras; no alcanzan a llegar a la importancia del determinismo de los genes. Estas corrientes reduccionistas y deterministas han estado tratando de probar sus teorías clasificando aleatoriamente a las personas y definiendo variables también en forma azarosa. Así, se ha tratado de demostrar que los genes influencian de tal manera la conducta, que las principales causas de criminalidad son genéticas. (Alper 1-17).

La metodología seguida para demostrar lo indemostrable ha sido clasificar arbitrariamente a los sujetos de estudio, descartar las influencias ambientales, y dejar que los prejuicios clasistas y racistas dicten las técnicas de estudio y las conclusiones. Así, se han usado las 'pruebas de inteligencia' 
diseñadas para la clase media acomodada de origen europeo, para probar que las personas afrodescendientes e indoamericanas son menos inteligentes que los europeos. Actualmente, bajo el título aparentemente neutro de "Investigación en genética de la conducta" se esconden estudios dedicados a convencer a la opinión pública que variaciones genéticas están detrás de las fluctuaciones de la conducta humana, tanto normal como patológica. En particular, numerosos estudios están abocados a encontrar las bases genéticas de la criminalidad y la violencia, para absolver los órdenes sociales y económicos injustos de responsabilidad por esas desviaciones. Es obvio que existen intereses poderosos detrás de estas investigaciones, que podrían sustentar enfoques que enfrenten al delito basadas en la represión a características individuales en lugar de corregir las graves injusticias sociales que alimentan el crimen.

Entre los investigadores conscientes de estos sesgos y prejuicios existe un sentimiento generalizado: No es ético investigar en el campo de la genética de la conducta. Precisamente porque estos estudios están monopolizados por tendencias reaccionarias y porque la correlación de fuerzas sociales es tal que las interpretaciones reduccionistas tenderán a primar. (Alper 1-17)

\section{La alteración de las características genéticas en células germinales es contraria a los principios de la bioética}

Recientemente un importante logro tecnocientífico ha sido el uso de sistemas enzimáticos que permiten cortar segmentos específicos de ADN de los genes y extraerlos del genoma, así como insertar segmentos nuevos de ADN en genes in vivo. Estos sistemas, conocidos como CRISPR por sus siglas en inglés (Clustered regularly interspaced short palindromic repeats) unidos a ciertas enzimas, como la Cas-9, pueden manipularse para literalmente editar segmentos del genoma: cambiar la secuencia de bases en los genes, borrar genes, agregar genes, etc. Este desarrollo tecnocientífico esta revolucionando la genómica pues pareciera que va a transformarse en un instrumento de terapia génica de gran precisión, para lograr hacer realidad la terapia génica en gran número de enfermedades hereditarias. Además, como la tecnología podría utilizarse también para 
editar el genoma de células germinales y embriones, se ha desarrollado una fuerte controversia bioética sobre su utilización. La extensión de éste artículo no permite una mayor elaboración, y solamente es mencionada para alertar al lector que debe estar pendiente de las grandes discusiones bioéticas que ya se están generando (Baltimore, et al. 36-38; Hsu, et al. 1262-1278; Lander, “Brave new genome").

\section{Conclusiones}

La principal objeción ética al uso de la genómica en la predicción de enfermedades y desviaciones de la conducta es que éstas suelen ser demasiado simplistas y basadas en conceptos reduccionistas que no tienen en cuenta la interacción de los genes con el medio ambiente. No sólo que los límites de la normalidad son arbitrarios, sino que estamos asistiendo a una medicalización y genetización de la vida y la salud, que son muy perniciosas para la ciencia misma y la humanidad. Es necesaria una concepción bio-psico-social más equilibrada de la naturaleza humana con reconocimiento de la importancia de lo ambiental y social para aprovechar en forma ética el desarrollo de la ciencia genómica para el bienestar y la salud humanas. Por otra parte, hoy más que nunca, es imprescindible un compromiso de los científicos y los tomadores de decisiones políticas de prohibir la alteración genética en células germinales.

\section{Lista de referencias}

Abuelas de Plaza de Mayo. Las abuelas y la genética. Buenos Aires: Publicación de Abuelas de Plaza de Mayo, 2009. 8 ago 2016 < https:// www.abuelas.org.ar/archivos/publicacion/LibroGenetica.pdf $>$.

Alper JS, et al. The Double-Edged Helix. Social Implications in a Diverse Society. Baltimore: The Johns Hopkins University Press, 2002.

Annas, GJ. "Rules for research on human genetic variation. Lessons from Iceland". N Engl J Med 342 (2000): 1830-1833.

Baltimore, D., et al. A prudent path forward for genomic engineering and germline gene modification. Science 348.6230 (2015): 36-38. 
Duster, T. "Race and reification in science". Science 307 (2005): 10501051.

Evans, JP, et al. "Deflating the genomic bubble". Science 331.6019 (2011): 861-862.

Holtzman, N. Proceed with caution. Genetic Risks in the Recombinant DNA Era. Baltimore: Johns Hopkins University Press, 1989.

Hsu PD, Lander ES, Zhang F. Development and Applications of CRISPRCas9 for Genome Engineering. Cell 157: 1262-1278, June 5, 2014. Lander, ES. "Brave new genome". New Engl J Med 373.1 (2015): 5-8.

Lewontin RC. The doctrine of DNA: Biology as ideology. New York: Penguin Books, 1991.

OECD. Guidelines for Human Biobanks and Genetic Research Databases. 2009. 8 ago. 2016 <www.oecd.org/st//biotechnology/hbgrd>.

Penchaszadeh VB. "Ética de la Investigación en Genética Humana". Ética de la Investigación en Biomedicina y Salud Pública. Ed. Keyeux, G, VB Penchaszadeh y A. Saada. México: UNESCO, 2006.

_. "Aspectos éticos y sociales de las pruebas genéticas y el asesoramiento genético". Asesoramiento Genético en la Práctica Médica. Ed. Delgado Rubio A, et al. Madrid: Editorial Médica Panamericana, 2011. 153-162.

_. Genética y Salud. Buenos Aires: EUDEBA, 2009.

_. (2012a). "Genética, reduccionismo y derecho a la salud". Genética y Derechos Humanos. Encuentros y Desencuentros. Comp. VB Penchaszadeh. Buenos Aires: Paidós, 2012. 177-204.

- (2012b) Uso de la identificación genética en la reparación de la violación del derecho a la identidad durante la dictadura militar argentina. En: VB Penchaszadeh (comp): Genética y Derechos Humanos. Encuentros y Desencuentros. Buenos Aires, Paidós, 2012, pp 263-298.

Rose, S. "A perturbadora ascencao do determinismo neurogenético". Ciéncia Hoje 21.126 (1997): 18-27.

UNESCO. Declaración universal sobre el genoma humano y los derechos humanos. 1997. 8 ago. 2016 <www.unesco.org/human_rights/ hrbc.htm>.

UNESCO. Declaración internacional sobre datos genéticos humanos. $2003<$.www.unesco.org/confgen/2003/genetic/>. 
Willet, WC. "Balancing life-style and genomics research for disease prevention". Science 296 (2002): 695-698.

World Health Organization. Community genetics Services. Report of a consultation on community genetics in low- and middle-income countries. 2010. 8 ago. 2016

<http://apps.who.int/iris/bitstream/10665/44532/1/9789241501149_ eng.pdf $>$.

World Health Organization. Genetic databases: assessing the benefits and the impact on human and patient rights. Geneva: World health Organization, 2003. 